\title{
Pharmacological Treatment of Parkinson's Disease
}

\author{
Insha Zahoor ${ }^{1,2} \bullet$ Amrina Shafi $^{2} \bullet$ Ehtishamul Haq ${ }^{1,2}$
}

${ }^{1}$ Bioinformatics Centre, University of Kashmir, Srinagar, J\&K, India;

${ }^{2}$ Department of Biotechnology, School of Biological Sciences, University of Kashmir, Srinagar, J\&K, India

Author for correspondence: Insha Zahoor, Bioinformatics Centre, Ground Floor, Science Block, University of Kashmir, Hazratbal, Srinagar, J\&K, 190006, India. E-mail: inshazahoor11@gmail.com

Doi: http://dx.doi.org/10.15586/codonpublications.parkinsonsdisease.2018.ch7

\begin{abstract}
Parkinson's disease (PD) is one of the common chronic degenerative conditions of the nervous system. There is currently no cure for PD, but a number of drugs offer benefits in terms of controlling the motor symptoms. While these drugs can offer significant improvements to motor function, they may lead to problematic adverse effects, particularly as disease progresses. In this chapter, we focus on the drugs that are currently employed for the treatment of $\mathrm{PD}$, including discussion on their mode of action, clinical utility, and adverse effects. We also cover some interesting emerging approaches that are currently under investigation.
\end{abstract}

Keywords: Clinical trials; Dopamine; Emerging treatments; Management; Parkinson's disease; Pharmacological treatment

In: Parkinson's Disease: Pathogenesis and Clinical Aspects. Stoker TB, Greenland JC (Editors). Codon Publications, Brisbane, Australia. ISBN: 978-0-9944381-6-4; Doi: http://dx.doi. org/10.15586/codonpublications.parkinsonsdisease.2018

Copyright: The Authors.

Licence: This open access article is licenced under Creative Commons Attribution 4.0 International (CC BY 4.0). https://creativecommons.org/licenses/by-nc/4.0/ 


\section{INTRODUCTION}

Parkinson's disease (PD) is a gradually progressive neurodegenerative condition. The etiology and pathogenesis remain incompletely understood. There are currently no disease-modifying treatments for $\mathrm{PD}$, and medical management is predominantly focused on controlling the motor symptoms using drugs. The long-term duration of disease means that patients may take sophisticated medication regimes aimed at controlling the motor symptoms, with a likelihood of problematic side effects. The movement disorder of PD occurs largely due to the selective loss of neurons in the substantia nigra pars compacta, with consequent depletion of dopamine in the striatum (1-3). Dopaminergic drugs designed to replace the action of dopamine in the deplete striatum form the mainstay of PD treatment at present.

This may be achieved through drugs that are metabolized to dopamine, that activate the dopamine receptor, or that prevent the breakdown of endogenous dopamine (4-6). There is no gold standard of treatment strategy, with medication regimes being tailored to the individual patient, based on the severity and temporal nature of their symptoms, as well as the side effects that they experience (1-4). In this context, this chapter will discuss treatment strategies involving pharmacological agents, with major emphasis on dopamine replacement therapies.

\section{DOPAMINE BIOSYNTHESIS AND METABOLISM}

Dopamine is incapable of crossing the blood-brain barrier (BBB), and it must be produced within the central nervous system (CNS) in order to act in the striatum. It is primarily synthesized in dopamine-producing neurons (dopaminergic neurons) within the brain, with small amounts of dopamine also being produced in the medulla of the adrenal glands (7). Here, we discuss the pathway pertaining to dopamine synthesis within the CNS.

In the classical biosynthetic pathway of dopamine, the direct metabolic precursor is L-dihydroxyphenylalanine (levodopa or L-DOPA) which is synthesized either directly from tyrosine (a non-essential amino acid) or indirectly from phenylalanine (an essential amino acid) (8). L-phenylalanine is converted into L-tyrosine in the liver, by the enzyme phenylalanine hydroxylase (PH) in the presence of oxygen, iron, and tetrahydrobiopterin as cofactors $(8,9)$. Tyrosine produced in the liver is then transported by an active transport mechanism into the dopaminergic neurons within the brain. This is followed by the conversion of L-tyrosine into L-DOPA through hydroxylation at the phenol ring by the enzyme tyrosine hydroxylase (TH). Subsequently, L-DOPA is converted into 3,4-dihydroxyphenethylamine (dopamine) through decarboxylation by the enzyme L-3,4-dihydroxyphenylalanine decarboxylase (DOPA decarboxylase) in the pre-synaptic terminal (8). DOPA decarboxylase is also known as aromatic-Lamino acid decarboxylase (AADC) due to its action on all naturally occurring aromatic L-amino acids, in addition to L-DOPA. Furthermore, under specific conditions, dopamine can also be synthesized by a minor pathway, in which 
L-tyrosine is converted into p-tyramine (mediated by AADC), with subsequent hydroxylation to dopamine by the enzyme CYP2D6 (Cytochrome P450 2D6) which is found in the substantia nigra of human brain (10-12).

Dopamine is metabolized after reuptake into dopaminergic neurons or glial cells (13). It undergoes oxidative deamination, catalyzed by the enzyme monoamine oxidase (MAO) in the presence of flavin adenine dinucleotide (FAD), to produce reactive aldehyde 3,4-dihydroxyphenylacetaldehyde (DOPAL). DOPAL is inactivated by conversion to 3,4-dihydroxyphenylethanol (DOPET) by alcohol dehydrogenase (ADH) or to 3,4-dihydroxyphenylacetic acid (DOPAC) by aldehyde dehydrogenase (ALDH) (13). DOPAC is then degraded to the biologically inactive metabolite homovanillic acid (HVA) by the enzyme catechol-O-methyl transferase (COMT). Alternatively, dopamine is metabolized to 3-methoxytyramine by COMT, which is in turn converted to 3-methoxy4-hydroxyacetaldehyde by MAO. The aforementioned ALDH then converts this to HVA, which is excreted in the urine (8). These pathways are illustrated in Figure 1.

Multiple components in this pathway have been targeted for the treatment of PD. For example, genes encoding the rate-limiting enzymes for dopamine synthesis, TH and AADC, formed part of the experimental lentiviral gene therapy ProSavin (Oxford Biomedica) which has been trialled in PD patients (14). Levodopa forms the mainstay of PD treatment regimes, with inhibitors of the metabolic enzymes MAO-B and COMT also being used. These drugs are discussed in detail in the remainder of this chapter.

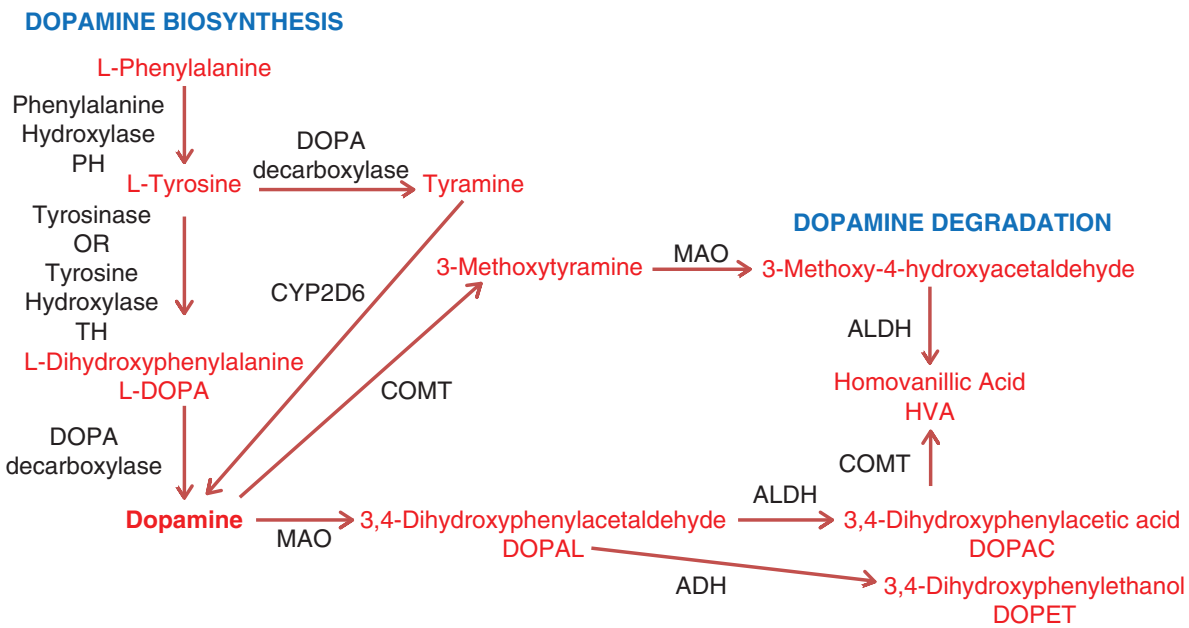

Figure 1 Metabolic pathway of dopamine synthesis and clearance. Dopamine is synthesized from phenylalanine or tyrosine via sequential reactions catalyzed mainly by $\mathrm{PH}, \mathrm{TH}$, and DOPA decarboxylase. It can also be synthesized from tyramine in a minor pathway by CYP2D6. Dopamine is effectively degraded into the main inactive metabolites DOPAC and HVA via a series of reactions mediated predominantly by the enzymes MAO, COMT, ALDH, and $\mathrm{ADH}$. 


\section{CURRENT TREATMENTS}

There are currently no disease-modifying drugs for PD, but the treatments that are used can offer significant symptomatic relief of the motor symptoms. They offer little clinical benefit in terms of the non-motor manifestations of PD. It is usual practice to delay the initiation of treatment until the patient's symptoms become troubling, to reduce the impact of adverse effects.

\section{Levodopa}

The mainstay of current PD treatment are levodopa-based preparations, designed to replace the dopamine in the depleted striatum. As is described above, dopamine itself is unable to cross the BBB and cannot be used to treat PD (2). In contrast, the dopamine precursor levodopa is able to cross the BBB and can be administered as a therapy. After absorption and transit across the BBB, it is converted into the neurotransmitter dopamine by DOPA decarboxylase (6) (Figure 1). It is usual practice for patients to be commenced on a low dose of levodopa, with the dose being titrated up based on the patient's response to treatment, balanced against the adverse effects experienced. Most patients require a dose in the range of 150-1000 mg daily, divided into multiple doses (15). Increasing doses result in elevated risk of developing problematic adverse effects, as discussed below (15). Generally, the clinical effect of levodopa is noticed quickly, and may last for several hours, particularly in the early stages of disease (15). However, as disease becomes more advanced, the effect of the drug usually wears off after shorter durations, and an increased frequency of dosing is often required.

Levodopa, though effective, comes with significant side effects that constitute an important part of the illness experienced by the patient, particularly in advanced disease. Some of its associated side effects result from the conversion of levodopa to dopamine outside the CNS (peripheral conversion) by DOPA decarboxylase $(6,16)$. These effects are minimized by administering levodopa in combination with peripheral inhibitors of DOPA decarboxylase, as is discussed below. Prolonged use can result in significant motor complications, including dyskinesias, and severe on-off motor fluctuations (6).

Dyskinesias are involuntary twisting hyperkinetic movements, which usually occur when the drug is at peak dose (but may also occur as the drug is wearing-off or even during off-periods) $(17,18)$. The emergence of problematic dyskinesias may be treated by a reduction in levodopa dose, meaning that a difficult balance must be struck between optimizing the control of the motor symptoms, while minimizing the adverse effects. In patients that have previously responded well to levodopa, but that have developed problematic dyskinesias, deep brain stimulation may be considered, which may allow for the control of motor symptoms on a reduced dose of levodopa. This is discussed in detail in Chapter 8. The on-off phenomenon refers to the fact that patients with advanced PD may experience rapid fluctuations in their motor function. During the "on" state, motor symptoms are controlled relatively well, but rapid wearing-off of the effect of levodopa leaves the patient in the "off" state, in which they have severe Parkinsonian motor features. These fluctuations can be particularly problematic and severely 
limit function. The probable causes of these motor symptoms are variable drug absorption and transit across the BBB, and resultant fluctuations in pre-synaptic and post-synaptic dopamine levels in the nigrostriatal pathway (19-25). Other important side effects include gastrointestinal disturbances such as nausea and vomiting, and orthostatic hypotension. Neuropsychiatric features including anxiety and hallucinations may occur due to "off-target" effects of dopamine acting in extranigral brain regions $(6,16)$.

Some strategies used to counteract the adverse effects of levodopa include using the minimum effective dose, fractionation of the dose, and the use of alternative dopaminergic treatments. Historically, temporary withdrawal of levodopa was used ("levodopa holidays"), but this is no longer recommended $(6,26)$. To reduce its peripheral side effects, levodopa is administered in combination with DOPA decarboxylase inhibitors such as benserazide and carbidopa. These compounds do not cross the $\mathrm{BBB}$, but selectively prevent the peripheral conversion of levodopa to dopamine, thereby reducing the peripheral side effects $(27,28)$. The most frequently prescribed combination drugs are carbidopa/levodopa (co-careldopa [trade names Sinemet, Pharmacopa, Atamet]) and benserazide/ levodopa (co-beneldopa [trade name Madopar]) (29). These compounds are available in several formulations, including modified release preparations, which can be useful for controlling symptoms overnight, and limiting early morning symptoms, as well as suspensions, which can be useful for patients that have swallowing difficulties $(6,29-31)$.

More recently, continuous intestinal infusion of levodopa gel (Duodopa [AbbVie Limited] — a combination of levodopa with carbidopa) has shown to be effective in terms of decreasing severe motor fluctuations when compared to oral levodopa-probably a result of more consistent levodopa absorption. However, this treatment is currently prohibitively expensive for widespread use (29). Researchers continue to focus on the development of other long-acting oral preparations as well as other modes of drug delivery, which may allow for improved clinical efficacy and side-effect profiles in the future (29).

\section{Dopamine agonists}

Dopamine receptor agonists came into the market for the treatment of PD in 1978. The commonly used agonists contain an ethanolamine moiety, and they may be categorized into ergot and non-ergot derived, based on receptor specificities (see Table 1) (32). These drugs stimulate the activity of the dopamine system by binding to the dopaminergic receptors and, unlike levodopa, do not need to be converted into dopamine $(2,6)$. Dopamine agonists are often prescribed as an initial therapy for PD, particularly in younger patients $(6,33)$. This approach allows for a delay in the use of levodopa, which may reduce the impact of the problematic motor complications, discussed above $(6,33)$. Some of the drugs listed in Table 1 are no longer used in clinical practice, as significant idiosyncratic adverse effects were observed. For example, pergolide was withdrawn as a treatment in 2007, after studies found that it was associated with a risk of pericardial, retroperitoneal, and pleural fibrosis (34).

Some of these drugs are available in controlled or prolonged release formulations in the form of tablets, patches, and injections. Rotigotine patches, 


\section{TABLE 1 Classification of dopamine agonists}

\begin{tabular}{ll} 
Ergot derived & Non-ergot derived \\
\hline Bromocriptine (Parlodel, Oral) & Apomorphine (Apokyn, Subcutaneous) \\
Pergolide (Permax, Oral) & Pramipexole (Mirapex, Oral) \\
Cabergoline (Oral) & Ropinirole (Requip, Oral) \\
Lisuride (Oral) & Rotigotine (NeuPro, Transdermal Patch)
\end{tabular}

for example, are useful in patients that are unable to take oral medications, for example, when they are kept nil-by-mouth in preparation for surgery. Switching a patient onto rotigotine patches in this setting requires calculation of the levodopa-equivalent dose of their existing treatment regime, to ensure that they are adequately medicated. While they may be less effective than levodopa in controlling the motor symptoms of $\mathrm{PD}$, with the majority of patients ultimately requiring levodopa therapy, dopamine agonists can be useful in patients with minor symptoms, in those that are unable to tolerate levodopa, or as an adjunct to levodopa therapy.

The drug half-life, and therefore duration of action, varies with patients and the type of agonist prescribed (6). On initiation of dopamine agonists, the dose is usually gradually increased, based on the patient's response and the side effects experienced (6). Of the commonly prescribed dopamine agonists, the usual dosing is as follows: $9-16 \mathrm{mg}$ (maximum $24 \mathrm{mg}$ ) total daily dose for ropinirole, divided into three to four doses; up to $3.3 \mathrm{mg}$ total daily dose of pramipexole, divided into three doses; and 4-6 mg once daily for rotigotine (35). Apomorphine is used less frequently but can be useful in relieving severe "off" episodes when given as a subcutaneous injection, or in patients with severe motor fluctuations (despite optimization of other medications), as a subcutaneous infusion. Some preclinical and imaging studies have suggested that dopamine agonists may possess antioxidant properties and lead to reduced loss of dopaminergic neurons, though there is no convincing evidence that these drugs offer a disease-modifying effect (36-40).

Treatment with dopamine agonists has been shown to result in a reduced incidence and severity of dystonia, motor fluctuations, and dyskinesia in comparison to levodopa $(6,33)$. However, they may cause other severe adverse effects $(41)$. Common side effects include nausea and vomiting (which occurs due to stimulation of the area postrema, situated in the medulla at a site in which the BBB is disrupted), dry mouth, insomnia, peripheral edema, constipation, fainting, hallucinations, and sleepiness $(2,6,33)$.

Perhaps, the most important adverse effect of dopamine agonists is the development of compulsive and impulsive behavioral problems (impulse control disorder [ICD]). Symptoms may include hypersexuality, gambling, binge eating, compulsive buying/shopping, punding, and hobbyism (compulsive Internet use, artistic endeavors, and writing) (42-48). It is important that clinicians are vigilant for such problems after initiation of dopamine agonists because they can result in 
significant issues for the patient, from a financial and social perspective. ICD may result in problems with interpersonal relations, caregiver well-being, and quality of life. Certain behaviors may be more common in males (e.g. hypersexuality) or females (e.g. compulsive shopping), and ICD is more common in those with a history of addiction (e.g. to alcohol or gambling) (41). ICD occurs in 15-20\% of PD patients taking dopamine agonists (there is also an increased risk of ICD with levodopa, though this is much less than that associated with dopamine agonists) $(49,50)$. Proposed mechanisms have included the action of dopamine agonists on the mesolimbic dopaminergic pathway, orbitofrontal cortex, and opiate and serotonin systems $(42,47)$.

Another important consideration is the risk of dopamine agonist withdrawal syndrome (DAWS), which may occur when a person with compulsive or impulsive behavior either stops taking or reduces the dosage of dopamine agonists (48). Symptoms of withdrawal syndrome may include anxiety, panic attacks, insomnia, irritability, dysphoria, agitation, fatigue, orthostatic hypotension, diaphoresis, and drug cravings (51). Thus, withdrawal of dopamine agonists must be performed cautiously, with clinical vigilance for these problems. As with ICD, DAWS can result in significant psychosocial consequences.

\section{Monoamine Oxidase B (MAO-B) inhibitors}

Other PD medications work by inhibiting the enzymes involved in dopamine metabolism, which preserves the levels of endogenous dopamine. One such class is the MAO-B inhibitors. As is discussed above, MAO-B is one of the main enzymes involved in the breakdown of dopamine, and reducing the activity of this enzyme therefore results in increased dopaminergic activity within the striatum, mediated by endogenous dopamine (see Figure 1) (6). Their use relieves motor symptoms in PD patients, and as with dopamine agonists they may be used as an initial treatment option, to delay the need for levodopa therapy, to reduce the risk of levodopa-induced motor complications (33). While they are sometimes sufficient for control of symptoms in early disease, most patients ultimately require levodopa-based treatment. MAO-B inhibitors may also be used in combination with levodopa-based preparations, to allow for a reduction in the levodopa dose.

Commonly used MAO-B inhibitors include selegiline (Deprenyl, Eldepryl, Zelapar) and rasagiline (Azilect). More recently, the drug safinamide (Xadago) was also approved for use in $\mathrm{PD}$, which appears to have multiple modes of action, one of which is thought to be inhibition of MAO-B (52). The recommended dosage for selegiline is 5-10 $\mathrm{mg}$ daily, and for rasagiline it is $0.5-1 \mathrm{mg}$ once daily (35). MAO-B inhibitors are generally well tolerated, with gastrointestinal side effects being the most common problem. Other adverse effects include aching joints, depression, fatigue, dry mouth, insomnia, dizziness, confusion, nightmares, hallucinations, flu-like symptoms, indigestion, and headache $(6,33)$.

\section{Catechol-O-methyl transferase inhibitors}

As is discussed above, another enzyme that is involved in dopamine degradation is COMT (Figure 1). Inhibitors of COMT therefore also offer a therapeutic means of preserving endogenous dopamine levels, by reducing its breakdown $(6,33)$. 
These are predominantly used as adjunctive therapy to levodopa, prolonging its duration of action by increasing its half-life and its delivery to the brain. In some patients, this allows for control of motor symptoms, with a reduction in off time in comparison to standard levodopa/DOPA decarboxylase inhibitor combinations (36). They are often prescribed to the patients when end-of-dose "wearingoff" is a particular problem, with levodopa therapy alone.

COMT inhibitors come in the form of tablets and are not generally prescribed as monotherapy, as on their own they offer only limited effect on PD symptoms. Examples of COMT inhibitors include entacapone (Comtan), tolcapone (Tasmar), and opicapone (Ongentys). Entacapone is often used in a combination preparation along with carbidopa and levodopa (Stalevo, Sastravi) $(6,35)$. The typical dosage for entacapone is $200 \mathrm{mg}$ four to eight times a day with each levodopa dose and $100 \mathrm{mg}$ three times a day in the case of tolcapone-the two most commonly used COMT inhibitors. It should be noted that COMT inhibitors can lead to the amplification of levodopa-induced side effects, including dyskinesias, and it may be that they necessitate a reduction in the levodopa dose (35). Tolcapone is associated with an uncommon, but potentially serious, risk of hepatotoxicity, and as such entacapone is generally preferred (35). Treatment with tolcapone therefore warrants monitoring of liver function tests. Other uncommon side effects include sleepiness, nausea, loss of appetite, diarrhea, dizziness, orange urine discoloration, hallucinations, abdominal pain, headaches, confusion, dry mouth, and chest pain $(6,35)$.

\section{Anticholinergics}

The medications that have so far been discussed are all designed to increase dopaminergic activity in the striatum. There are a small number of drugs used in the treatment of PD that act through non-dopaminergic mechanisms. One such class of drugs are the anticholinergics. These reduce the activity of the neurotransmitter acetylcholine, by acting as antagonists at cholinergic receptors (35). While their role is limited and they are now prescribed infrequently, they may offer some benefit in improving rigidity and tremor in PD (53). Loss of dopaminergic neurons results in disturbance of the normal balance between dopamine and acetylcholine in the brain, and anticholinergic drugs may lead to restoration and maintenance of the normal balance between these two neurotransmitters (33).

The main role of these drugs is in young patients at early stages of the disease for the relief of mild movement symptoms-particularly tremors and muscle stiffness (35). Anticholinergic drugs play more of a role in tremor-predominant PD, where they may be used as monotherapy in the early stages. However, when anticholinergics are used, they are usually done so in combination with levodopa and the other aforementioned medications. They are generally avoided in elderly patients or those with cognitive problems, due to an increased risk of confusion with this class of drugs (35). Tablet and oral suspension preparations exist. Examples of anticholinergics include benztropine, orphenadrine, procyclidine, and trihexyphenidyl (Benzhexol) (35). The common adverse effects include blurred vision, dry mouth, constipation, drowsiness, trouble urinating, urinary retention, confusion, cognitive impairment, hallucinations, dizziness, trouble swallowing, dyskinetic movements, and memory problems. Although dry mouth is listed as an adverse effect of anticholinergics, in patients in whom drooling is a 
particular problem, the reduced salivation brought on by anticholinergic drugs is a desirable effect, and they may actually be used in the treatment of this symptom $(33,35,36)$.

\section{Amantadine}

Initially, amantadine (Symmetrel) was developed as an antiviral drug for treating flu, but it has subsequently been used for the treatment of PD. It may be used for the treatment of rigidity, rest tremor, and sometimes fatigue, and may offer a short-lived improvement in symptoms. It may also allow for a lower dose of levodopa to be used, reducing the risk of dyskinesia. However, its most useful property is probably the fact that it can be used to limit the severity of levodopa-induced dyskinesias (54). It should be noted that the evidence for the use of amantadine in controlling PD symptoms is limited, with a 2003 Cochrane review concluding that there was insufficient evidence to recommend its use in PD (55).

Chemically, it is the derivative of adamantine as 1-adamantylamine or l-aminoadamantane. It is not known how amantadine may have an antiParkinsonian effect, but it acts as a weak glutamate antagonist at the N-methyl-Daspartate receptor (NMDAR) (54). Like most of the other anti-Parkinson drugs that have been discussed, it is started with a low dose and is titrated up. It comes in the form of tablets and liquid syrup. While generally well tolerated, possible side effects associated with the use of amantadine include hallucinations, confusion and impaired concentration, livedo reticularis, leg swelling, blurred vision, nausea and vomiting, appetite loss, insomnia and nightmares, sweating, agitation, and headache (35).

\section{EMERGING TREATMENTS}

The drugs that have been discussed are used to control the symptoms of PD, but none of them alter the course of disease. While there are currently no diseasemodifying treatments for $\mathrm{PD}$, a number of promising novel approaches are currently under investigation $(56,57)$. As well as new experimental compounds, there is also much interest in drug repurposing - the use of drugs that have an established clinical indication-in a new setting. Because such drugs have been used previously, safety data already exist, so progress through clinical trials may potentially be expedited. In addition to new drugs, there are a number of regenerative approaches currently in, or about to enter, clinical trials. These include gene therapies, such as ProSavin-a lentivirus vector carrying the genes encoding DOPA decarboxylase, TH, and guanosine triphosphate cyclohydrolase-1 (GTPCH1) and stem cell approaches (with the latter being discussed in detail in Chapter 9) $(14,57)$. These regenerative treatments are not designed to offer a diseasemodifying effect but to restore dopaminergic activity in the striatum in a more physiological fashion than what is currently achieved with dopaminergic medications, theoretically with a reduced risk of the adverse effects of levodopa (58).

There is a plethora of evidence suggesting that alpha-synuclein ( $\alpha$-synuclein) aggregation plays a central role in the pathogenesis of $\operatorname{PD}(59,60)$. Thus, there is 
much interest in how this process may be targeted by potential therapies. Therapeutic approaches have been developed aiming to:

(i) reduce $\alpha$-synuclein production

(ii) inhibit $\alpha$-synuclein aggregation

(iii) increase intracellular and extracellular degradation of $\alpha$-synuclein aggregates

(iv) reduce uptake of extracellular $\alpha$-synuclein by neighboring cells (56)

Immunotherapies targeting $\alpha$-synuclein are now beginning to enter clinical testing. Recently, a Phase 1 clinical trial with the synthetic vaccine AFFITOPE PD03A, containing an $\alpha$-synuclein mimicking peptide, has been completed by Affiris (61). This formulation was tested in 36 patients with early stage PD, who received the vaccine subcutaneously, and it was found to be very well tolerated, with only mild side effects. An $\alpha$-synuclein-targeting passive immunotherapeutic agent PRX002 (Prothena) has also been tested in Phase la and Phase lb clinical trials. This is a humanized monoclonal antibody with which a $96.5 \%$ reduction in free serum levels of $\alpha$-synuclein was observed $(62,63)$. No major side effects or toxicity occurred, and the drug has progressed to Phase 2 clinical trials (64). Another $\alpha$-synuclein-based passive immunotherapy, BIIB-054 (Biogen), was found to be well tolerated with a satisfactory pharmacokinetic profile $(65,66)$. A number of other experimental immunotherapeutic agents are also under investigation (67-69). In addition, drugs aiming to result in increased extracellular degradation of $\alpha$-synuclein are being considered as potential therapeutic options for $\mathrm{PD}$, for example, the serine protease Kallikrein 6 (KLK6 or neurosin) $(70,71)$.

In addition to increasing $\alpha$-synuclein clearance, another potential avenue would be to reduce $\alpha$-synuclein production, which may be achieved through RNA interference (RNAi) technology. Although this has not reached in-human trials, in vitro and animal studies have generated some interesting results. For example, short hairpin RNA (shRNA) targeting $\alpha$-synuclein has been delivered via a lentiviral vector to rats, which resulted in silencing of the expression of ectopic human $\alpha$-synuclein in the striatum. Small interfering RNA (siRNA) delivered into the mouse hippocampus also decreased the expression of endogenous $\alpha$-synuclein after a 2 -week infusion, with no signs of toxicity $(72,73)$. Subsequent use of siRNA in non-human primates demonstrated a reduction in $\alpha$-synuclein levels by $40-50 \%$. However, this approach did not progress toward clinical trials due to lack of funding (74). Rats treated with shRNA also demonstrated a reduction in $\alpha$-synuclein levels of 35\% (75). Of course, the concern with suppressing $\alpha$-synuclein levels to such a degree is that the normal function of the protein is lost. In some studies, significant reduction in $\alpha$-synuclein levels was accompanied by escalated neurotoxicity, with some even showing degeneration of nigrostriatal system (76-78). Extensive preclinical safety data will therefore be necessary if these techniques are to enter clinical trials.

Another approach for reducing $\alpha$-synuclein production involves reducing its expression at a transcriptional level. Beta-2-adrenoreceptor (beta-2AR) agonists, such as clenbuterol, have been suggested to do this, and have achieved a greater than 35\% reduction in $\alpha$-synuclein expression in a neuroblastoma cell-line and in rat cortical neurons (79). It has been postulated that they act by histone 3 lysine 27 acetylation of $\alpha$-synuclein promoters and enhancers. Supportive evidence for a potential benefit of these drugs comes from two epidemiological studies carried out in Norway involving very large numbers of patients, suggesting that beta-2AR 
agonists warrant further investigation, and that they may play a role in PD treatment in the future (79).

Of the other existing drugs being considered for repurposing, two have entered clinical trials - the chemotherapy agent, nilotinib, and the glucagon-like peptide-1 receptor agonist, exenatide. Nilotinib is a c-Abl tyrosine kinase inhibitor used in the treatment of chronic myelogenous leukemia (CML). Activity of c-abl has been found to be enhanced in brain tissue of PD patients, which may lead to increased phosphorylation and aggregation of $\alpha$-synuclein, and/or reduced function of the Parkin protein involved in mitochondrial biogenesis (80). Nilotinib attenuated $\alpha$-synuclein levels in A53T transgenic mice and also provided a degree of neuroprotection (81). It has been observed to be well tolerated by PD patients albeit at a much lower dosage than what is usually prescribed for the treatment of CML (82). Following these observations, nilotinib has entered a Phase 2a trial in 2017, and there is much hope about its treatment potential (83). However, a potential limitation to the use of $\mathrm{c}-\mathrm{abl}$ inhibitors in PD is the poor transit across the $\mathrm{BBB}$, and novel agents may need to be developed to circumvent this.

Similarly, exenatide, an established treatment for type 2 diabetes mellitus, is emerging as a promising therapeutic option for PD. Neuroprotective potential has been seen in preclinical models of the disease, with persistent clinical improvements observed in an initial clinical trial (84). Thereafter, it was taken forward to a single-center, randomized, double-blind, placebo-controlled Phase 2 clinical trial in which a weekly dosage of $2 \mathrm{mg}$ was administered to patients subcutaneously (85). Similarly, improvements in motor scores were observed, which persisted even beyond discontinuation of treatment.

\section{CONCLUSION}

The current treatments available for PD are designed to restore dopaminergic activity in the dopamine-deplete striatum of PD patients, with consequent improvement in motor symptoms. Disappointingly, there is a paucity of pharmacological options for treatment of the non-motor features, which are unfortunately often the most disabling aspects of disease. At the present time, there are no established treatments able to slow, stop, or modify the disease course. Commonly used drugs for PD include those based on exogenous administration of compounds with dopaminergic activity (e.g. levodopa, dopamine agonists), and those that inhibit the metabolism of endogenous dopamine (e.g. COMT, MAO-B inhibitors) (6). While levodopa can cause significant adverse effects, the vast majority of patients ultimately require treatment with this drug. It is important to note that there is no standard treatment regime for $\mathrm{PD}$, with each patient being treated with a tailored approach taking into account the severity of their symptoms and temporal nature of these, the side effects that they experience, and their personal priorities.

While there have been few major developments in the field of PD treatment since the introduction of levodopa, numerous experimental therapeutic approaches are currently under investigation. These include drugs that specifically target $\alpha$-synuclein pathology - widely considered to be the driver of neurodegeneration in PD. These drugs offer hope that a disease-modifying agent will be identified in 
the short- to medium-term future. In combination with a number of regenerative approaches, including stem cells and gene therapies, therapeutics of PD is likely to see significant advances over the coming years, with a number of novel, effective options likely to become available to clinicians in the foreseeable future.

Conflict of interest: The authors declare that they have no conflicts of interest with respect to research, authorship, and publication of this book chapter.

Copyright and permission statement: We confirm that the materials included in this chapter do not violate copyright laws. Where relevant, appropriate permissions have been obtained from the original copyright holder(s). All original sources have been appropriately acknowledged and/or referenced.

Acknowledgments: We are highly indebted to the Bioinformatics Centre, University of Kashmir, for providing their services while drafting this chapter.

\section{REFERENCES}

1. Jankovic J. Parkinson's disease: Clinical features and diagnosis. J Neurol Neurosurg Psychiatry. 2008;79(4):368-76. http://dx.doi.org/10.1136/jnnp.2007.131045

2. Samii A, Nutt JG, Ransom BR. Parkinson's disease. Lancet. 2004;363(9423):1783-93. http://dx.doi. org/10.1016/S0140-6736(04)16305-8

3. Sveinbjornsdottir S. The clinical symptoms of Parkinson's disease. J Neurochem. 2016;139 Suppl 1:318-24. http://dx.doi.org/10.1111/jnc.13691

4. AlDakheel A, Kalia LV, Lang AE. Pathogenesis-targeted, disease-modifying therapies in Parkinson disease. Neurotherapeutics. 2014;11(1):6-23. http://dx.doi.org/10.1007/s13311-013-0218-1

5. Connolly BS, Lang AE. Pharmacological treatment of Parkinson disease: A review. JAMA. 2014:311(16):1670-83. http://dx.doi.org/10.1001/jama.2014.3654

6. The National Collaborating Centre for Chronic Conditions ed. Symptomatic pharmacological therapy in Parkinson's disease. Parkinson's disease. London: Royal College of Physicians; 2006(ISBN 1-86016283-5). pp. 59-100.

7. Seeman P. Historical overview: Introduction to the dopamine receptors. In: Neve K, editor. The dopamine receptors. Springer; 2009; ISBN 978-1-60327-333-6. pp. 1-22.

8. Musacchio JM. Enzymes involved in the biosynthesis and degradation of catecholamines. In: Iverson L, editor. Biochemistry of biogenic amines. Springer; 2013 (ISBN 978-1-4684-3171-1). pp. 1-35.

9. Blascko H. The specific action of L-dopa decarboxylase. J Physiol. 1939;96(50):50-1.

10. Bromek E, Haduch A, Golembiowska K, Daniel WA. Cytochrome P450 mediates dopamine formation in the brain in vivo. J Neurochem. 2011;118(5):806-15. http://dx.doi.org/10.1111/j.1471-4159. 2011.07339.x

11. Hiroi T, Imaoka S, Funae Y. Dopamine formation from tyramine by CYP2D6. Biochem Biophys Res Commun. 1998;249(3):838-43. http://dx.doi.org/10.1006/bbrc.1998.9232

12. Wang X, Li J, Dong G, Yue J. The endogenous substrates of brain CYP2D. Eur J Pharmacol. 2014;724:211-18. http://dx.doi.org/10.1016/j.ejphar.2013.12.025

13. Eisenhofer G, Kopin IJ, Goldstein DS. Catecholamine metabolism: A contemporary view with implications for physiology and medicine. Pharmacol Rev. 2004;56(3):331-49. http://dx.doi.org/10.1124/ pr.56.3.1

14. Palfi S, Gurruchaga JM, Lepetit H, Howard K, Ralph GS, Mason S, et al. Long-term follow-up of a phase I/II study of ProSavin, a Lentiviral Vector Gene Therapy for Parkinson's disease. Hum Gene Ther Clin Dev. 2018 Sep;29(3):148-55. http://dx.doi.org/10.1089/humc.2018.081 
15. Mayo Clinic. [12th August 2018]. Available from: https://www.mayoclinic.org/drugs-supplements/ levodopa-oral-route/proper-use/drg-20064498

16. Nord M. Levodopa pharmacokinetics-from stomach to brain: A study on patients with Parkinson's disease. Linköping: Linköping University Electronic Press; 2017 (ISBN 9789176855577). pp. 1-72.

17. Fahn S. The spectrum of levodopa-induced dyskinesias. Ann Neurol. 2000;47(4 Suppl 1):S2-9; discussion S-11.

18. Jankovic J. Levodopa strengths and weaknesses. Neurology. 2002;58(4 Suppl 1):S19-32. http:// dx.doi.org/10.1212/WNL.58.suppl_1.S19

19. Cenci MA. Presynaptic mechanisms of L-DOPA-induced dyskinesia: The findings, the debate, and the therapeutic implications. Front Neurol. 2014;5:242. http://dx.doi.org/10.3389/fneur.2014.00242

20. Jenner P. Pharmacology of dopamine agonists in the treatment of Parkinson's disease. Neurology. 2002;58(4 Suppl 1):S1-8. http://dx.doi.org/10.1212/WNL.58.suppl_1.S1

21. Jenner P. Dopamine agonists, receptor selectivity and dyskinesia induction in Parkinson's disease. Curr Opin Neurol. 2003;16 Suppl 1:S3-7. http://dx.doi.org/10.1097/00019052-20031200100002

22. Bravi D, Mouradian MM, Roberts JW, Davis TL, Sohn YH, Chase TN. Wearing-off fluctuations in Parkinson's disease: Contribution of postsynaptic mechanisms. Ann Neurol. 1994;36(1):27-31. http://dx.doi.org/10.1002/ana.410360108

23. Di Monte DA, McCormack A, Petzinger G, Janson AM, Quik M, Langston WJ. Relationship among nigrostriatal denervation, parkinsonism, and dyskinesias in the MPTP primate model. Mov Disord. 2000;15(3): 459-66. http://dx.doi.org/10.1002/1531-8257(200005)15:3<459::AID-MDS1006>3.0.CO;2-3

24. Mouradian MM, Juncos JL, Fabbrini G, Schlegel J, Bartko JJ, Chase TN. Motor fluctuations in Parkinson's disease: Central pathophysiological mechanisms, Part II. Ann Neurol. 1988;24(3):372-8. http://dx.doi.org/10.1002/ana.410240304

25. Smith LA, Jackson MJ, Hansard MJ, Maratos E, Jenner P. Effect of pulsatile administration of levodopa on dyskinesia induction in drug-naive MPTP-treated common marmosets: Effect of dose, frequency of administration, and brain exposure. Mov Disord. 2003;18(5):487-95. http://dx.doi.org/10.1002/ mds. 10394

26. Pahwa R, Factor SA, Lyons KE, Ondo WG, Gronseth G, Bronte-Stewart H, et al. Practice Parameter: Treatment of Parkinson disease with motor fluctuations and dyskinesia (an evidence-based review): Report of the quality standards subcommittee of the American Academy of Neurology. Neurology. 2006;66(7):983-95. http://dx.doi.org/10.1212/01.wnl.0000215250.82576.87

27. Lotti VJ, Porter CC. Potentiation and inhbition of some central actions of L(-)-dopa by decarboxylase inhibitors. J Pharmacol Exp Ther. 1970 Apr;172(2):406-15.

28. Silva MA, Mattern C, Hacker R, Tomaz C, Huston JP, Schwarting RK. Increased neostriatal dopamine activity after intraperitoneal or intranasal administration of L-DOPA: On the role of benserazide pretreatment. Synapse. 1997;27(4):294-302. http://dx.doi.org/10.1002/(SICI)1098-2396(199712)27: 4<294::AID-SYN3>3.0.CO;2-7

29. Oertel WH. Recent advances in treating Parkinson's disease. F1000Research. 2017;6:260. http:// dx.doi.org/10.12688/f1000research.10100.1

30. Koller WC, Pahwa R. Treating motor fluctuations with controlled-release levodopa preparations. Neurology. 1994;44(7 Suppl 6):S23-8.

31. MacMahon DG, Sachdev D, Boddie HG, Ellis CJ, Kendal BR, Blackburn NA. A comparison of the effects of controlled-release levodopa (Madopar CR) with conventional levodopa in late Parkinson's disease. J Neurol Neurosurg Psychiatry. 1990;53(3):220-3. http://dx.doi.org/10.1136/ jnnp.53.3.220

32. Deleu D, Northway MG, Hanssens Y. Clinical pharmacokinetic and pharmacodynamic properties of drugs used in the treatment of Parkinson's disease. Clin Pharmacokinet. 2002;41(4):261-309. http:// dx.doi.org/10.2165/00003088-200241040-00003

33. Goldenberg MM. Medical management of Parkinson's disease. P\&T. 2008;33(10):590-606.

34. Shaunak S, Wilkins A, Pilling JB, Dick DJ. Pericardial, retroperitoneal, and pleural fibrosis induced by pergolide. J Neurol Neurosurg Psychiatry. 1999 Jan;66(1):79-81. http://dx.doi.org/10.1136/ jnnp.66.1.79 
35. Parkinson's Disease Toolkit. [12th August 2018]. Available from: http://www.toolkit.parkinson.org/ content/first-line-meds-and-dosing

36. Ahlskog JE. Slowing Parkinson's disease progression: Recent dopamine agonist trials. Neurology. 2003;60(3):381-9. http://dx.doi.org/10.1212/01.WNL.0000044047.58984.2F

37. Cassarino DS, Fall CP, Smith TS, Bennett JP, Jr. Pramipexole reduces reactive oxygen species production in vivo and in vitro and inhibits the mitochondrial permeability transition produced by the Parkinsonian neurotoxin methylpyridinium ion. J Neurochem. 1998;71(1):295-301. http://dx.doi. org/10.1046/j.1471-4159.1998.71010295.x

38. Olanow CW, Jenner P, Brooks DJ. Dopamine agonists and neuroprotection in Parkinson's disease. In: Olanow CW, Jenner P, editors. Beyond the decade of the brain. Tunbridge Wells, Kent: Wells Medical; 1998. pp. 331-40.

39. Whone AL, Watts RL, Stoessl AJ, Davis M, Reske S, Nahmias C, et al. Slower progression of Parkinson's disease with ropinirole versus levodopa: The REAL-PET study. Ann Neurol. 2003;54(1):93-101. http://dx.doi.org/10.1002/ana.10609

40. Zou L, Xu J, Jankovic J, He Y, Appel SH, Le W. Pramipexole inhibits lipid peroxidation and reduces injury in the substantia nigra induced by the dopaminergic neurotoxin 1-methyl-4-phenyl-1,2,3, 6-tetrahydropyridine in C57BL/6 mice. Neurosci Lett. 2000;281(2-3):167-70. http://dx.doi.org/ 10.1016/S0304-3940(00)00853-3

41. Ceravolo R, Rossi C, Del Prete E, Bonuccelli U. A review of adverse events linked to dopamine agonists in the treatment of Parkinson's disease. Expert Opin Drug Saf. 2016;15(2):181-98. http://dx.doi. org/10.1517/14740338.2016.1130128

42. Atmaca M. Drug-induced impulse control disorders: A review. Curr Clin Pharmacol. 2014;9(1):70-4. http://dx.doi.org/10.2174/1574884708666131111202954

43. Baumann-Vogel H, Valko PO, Eisele G, Baumann CR. Impulse control disorders in Parkinson's disease: Don't set your mind at rest by self-assessments. Eur J Neurol. 2015;22(4):603-9. http://dx.doi. org/10.1111/ene. 12646

44. Moore TJ, Glenmullen J, Mattison DR. Reports of pathological gambling, hypersexuality, and compulsive shopping associated with dopamine receptor agonist drugs. JAMA Intern Med. 2014;174(12): 1930-3. http://dx.doi.org/10.1001/jamainternmed.2014.5262

45. Saez-Francas N, Marti Andres G, Ramirez N, de Fabregues O, Alvarez-Sabin J, Casas M, et al. Clinical and psychopathological factors associated with impulse control disorders in Parkinson's disease. Neurologia. 2016;31(4):231-8. http://dx.doi.org/10.1016/j.nrleng.2015.05.008

46. Seeman P. Parkinson's disease treatment may cause impulse-control disorder via dopamine D3 receptors. Synapse. 2015;69(4):183-9. http://dx.doi.org/10.1002/syn.21805

47. van Eimeren T, Ballanger B, Pellecchia G, Miyasaki JM, Lang AE, Strafella AP. Dopamine agonists diminish value sensitivity of the orbitofrontal cortex: A trigger for pathological gambling in Parkinson's disease? Neuropsychopharmacology. 2009;34(13):2758-66. http://dx.doi.org/10.1038/ npp.2009.124

48. Weintraub D, Claassen DO. Impulse control and related disorders in Parkinson's disease. Int Rev Neurobiol. 2017;133:679-717. http://dx.doi.org/10.1016/bs.irn.2017.04.006

49. Weintraub D, Koester J, Potenza MN, Siderowf AD, Stacy M, Voon V, et al. Impulse control disorders in Parkinson disease: A cross-sectional study of 3090 patients. Arch Neurol. 2010;67:589-95. http:// dx.doi.org/10.1001/archneurol.2010.65

50. Poletti M, Logi C, Lucetti C, Del Dotto P, Baldacci F, Vergallo A, et al. A single-center, cross-sectional prevalence study of impulse control disorders in Parkinson disease: Association with dopaminergic drugs. J Clin Psychopharmacol. 2013;33:691-4. http://dx.doi.org/10.1097/JCP.0b013e3182979830

51. Rabinak CA, Nirenberg MJ. Dopamine agonist withdrawal syndrome in Parkinson disease. Archiv Neurol. 2010;67(1):58-63. http://dx.doi.org/10.1001/archneurol.2009.294

52. Bianchi MLE, Riboldazzi G, Mauri M, Versino M. Efficacy of safinamide on non-motor symptoms in a cohort of patients affected by idiopathic Parkinson's disease. Neurol Sci. 2018 Oct 31. http://dx.doi. org/10.1007/s10072-018-3628-3

53. Brocks DR. Anticholinergic drugs used in Parkinson's disease: An overlooked class of drugs from a pharmacokinetic perspective. J Pharm Pharm Sci. 1999;2(2):39-46. 
54. Sawada H, Oeda T, Kuno S, Nomoto M, Yamamoto K, Yamamoto M, et al. Amantadine for dyskinesias in Parkinson's disease: A randomized controlled trial. PLoS One. 2010;5(12):e15298. http://dx.doi. org/10.1371/journal.pone.0015298

55. Crosby N, Deane KH, Clarke CE. Amantadine in Parkinson's disease. Cochrane Database Syst Rev. 2003(1):CD003468. http://dx.doi.org/10.1002/14651858.CD003468

56. Brundin P, Dave KD, Kordower JH. Therapeutic approaches to target alpha-synuclein pathology. Exp Neurol. 2017;298(Pt B):225-35.

57. Stoker TB, Torsney KM, Barker RA. Emerging treatment approaches for Parkinson's disease. Front Neurosci. 2018 Oct 8;12:693. http://dx.doi.org/10.3389/fnins.2018.00693

58. Stoker TB, Barker RA. Regenerative therapies for Parkinson's disease: An update. BioDrugs. 2018 Aug;32(4):357-66. http://dx.doi.org/10.1007/s40259-018-0294-1

59. Kalia LV, Lang AE. Parkinson's disease. Lancet. 2015 Aug 29;386(9996):896-912. http://dx.doi. org/10.1016/S0140-6736(14)61393-3

60. Burré J, Sharma M, Südhof TC. Cell biology and pathophysiology of $\alpha$-synuclein. Cold Spring Harb Perspect Med. 2017:a024091-29.

61. Affiris Company Website. AFFiRiS announces top line results of first-in-human clinical study using AFFITOPE $®$ PD03A, confirming immunogenicity and safety profile in Parkinson's disease patients. 2017. Available from: http://www.affiris.comnewsaffiris-announces-topline-results-of-first-in-humanclinical-study-using-affitope

62. Schenk DB, Koller M, Ness DK, Griffith SG, Grundman M, Zago W, et al. First-in-human assessment of PRX002, an anti-alpha-synuclein monoclonal antibody, in healthy volunteers. Mov Disord. 2017;32(2):211-18. http://dx.doi.org/10.1002/mds.26878

63. Prothena Company Website. Clinical results presented from Prothena's phase 1b study of PRX002/ RG7935 demonstrating robust antibody CNS penetration and significant reduction of free serum alpha-synuclein in patients with Parkinson's disease. 2017a. Available from: http://ir.prothena.com/ releasedetail.cfm?ReleaseID $=1019672$

64. Prothena Company Website. Prothena announces initiation of phase 2 PASADENA study of PRX002/ RG7935 in patients with early Parkinson's disease. 2017b. Available from: http://ir.prothena.com/ releasedetail.cfm?Release $\mathrm{ID}=1032188$

65. Alzforum. $\alpha$-Synuclein antibodies enter phase 2, sans biomarker. 2017. Available from: http://www. alzforum.org/news/conference-coverage/synuclein-antibodies-enter-phase-2-sansbiomarker

66. Brys M, Hung S, Fanning L, Penner NM, Yang M, David E, et al. Randomized, double-blind, placebocontrolled, single ascending dose study of anti-alpha-synuclein antibody BIIB054 in healthy volunteers. 13th International Conference on Alzheimer's and Parkinson's Diseases (AD/PD 2017), Vienna, Austria, 02-Apr-2017.

67. Fagerqvist T, Lindstrom V, Nordstrom E, Lord A, Tucker SM, Su X, et al. Monoclonal antibodies selective for alpha-synuclein oligomers/protofibrils recognize brain pathology in Lewy body disorders and alpha-synuclein transgenic mice with the disease-causing A30P mutation. J Neurochem. 2013;126(1):131-44. http://dx.doi.org/10.1111/jnc.12175

68. BioArctic Company Website. BioArctic enters into collaboration with AbbVie for Parkinson's disease research. 2016. Available from: https://www.bioarctic.se/en/bioarctic-enters-intocollaboration-withabbvie-for-parkinsons-disease-research-2815/

69. AstraZeneca Company Website. AstraZeneca and Takeda establish collaboration to develop and commercialise MEDI1341 for Parkinson's disease. 2017. Available from: https://www.astrazeneca. com/media-centre/press-releases/2017/astrazeneca-and-takeda-establish-collaboration-to-developand-commercialise-medil34l-for-parkinsons-disease-25082017

70. Pampalakis G, Sykioti VS, Ximerakis M, Stefanakou-Kalakou I, Melki R, Vekrellis K, et al. KLK6 proteolysis is implicated in the turnover and uptake of extracellular alpha-synuclein species. Oncotarget. 2017;8(9):14502-15. http://dx.doi.org/10.18632/oncotarget.13264

71. Spencer B, Michael S, Shen J, Kosberg K, Rockenstein E, Patrick C, et al. Lentivirus mediated delivery of neurosin promotes clearance of wild-type alpha-synuclein and reduces the pathology in an alpha-synuclein model of LBD. Mol Ther. 2013;21(1):31-41. http://dx.doi.org/10.1038/ mt. 2012.66 
72. Lewis J, Melrose H, Bumcrot D, Hope A, Zehr C, Lincoln S, et al. In vivo silencing of alpha-synuclein using naked siRNA. Mol Neurodegener. 2008;3:19. http://dx.doi.org/10.1186/1750-1326-3-19

73. Sapru MK, Yates JW, Hogan S, Jiang L, Halter J, Bohn MC. Silencing of human alpha-synuclein in vitro and in rat brain using lentiviral-mediated RNAi. Exp Neurol. 2006;198(2):382-90. http://dx.doi. org/10.1016/j.expneurol.2005.12.024

74. McCormack AL, Mak SK, Di Monte DA. Increased alpha-synuclein phosphorylation and nitration in the aging primate substantia nigra. Cell Death Dis. 2012;3:e315. http://dx.doi.org/10.1038/ cddis. 2012.50

75. Zharikov AD, Cannon JR, Tapias V, Bai Q, Horowitz MP, Shah V, et al. shRNA targeting alpha-synuclein prevents neurodegeneration in a Parkinson's disease model. J Clin Invest. 2015;125(7):2721-35. http://dx.doi.org/10.1172/JCI64502

76. Collier TJ, Redmond DE, Jr., Steece-Collier K, Lipton JW, Manfredsson FP. Is alpha-synuclein lossof-function a contributor to Parkinsonian pathology? Evidence from non-human primates. Front Neurosci. 2016;10:12. http://dx.doi.org/10.3389/fnins.2016.00012

77. Gorbatyuk OS, Li S, Nash K, Gorbatyuk M, Lewin AS, Sullivan LF, et al. In vivo RNAi-mediated alphasynuclein silencing induces nigrostriatal degeneration. Mol Ther. 2010;18(8):1450-7. http://dx.doi. org/10.1038/mt.2010.115

78. Kanaan NM, Manfredsson FP. Loss of functional alpha-synuclein: A toxic event in Parkinson's disease? J Parkinson's Dis. 2012;2(4):249-67.

79. Mittal S, Bjornevik K, Im DS, Flierl A, Dong X, Locascio JJ, et al. beta2-Adrenoreceptor is a regulator of the alpha-synuclein gene driving risk of Parkinson's disease. Science. 2017;357(6354):891-8. http://dx.doi.org/10.1126/science.aaf3934

80. Lonskaya I, Hebron ML, Desforges NM, Schachter JB, Moussa CE. Nilotinib-induced autophagic changes increase endogenous parkin level and ubiquitination, leading to amyloid clearance. J Mol Med. 2014;92(4):373-86. http://dx.doi.org/10.1007/s00109-013-1112-3

81. Hebron ML, Lonskaya I, Moussa CE. Nilotinib reverses loss of dopamine neurons and improves motor behavior via autophagic degradation of alpha-synuclein in Parkinson's disease models. Hum Mol Genet. 2013;22(16):3315-28. http://dx.doi.org/10.1093/hmg/ddt192

82. Pagan F, Hebron M, Valadez EH, Torres-Yaghi Y, Huang X, Mills RR, et al. Nilotinib effects in Parkinson's disease and dementia with lewy bodies. J Parkinson's Dis. 2016;6(3):503-17. http:// dx.doi.org/10.3233/JPD-160867

83. The Michael J. Fox foundation. Phase Ila safety and tolerability trial of Nilotinib in people with Parkinson's disease. 2017. Available from: https://www.michaeljfox.org/foundation/grant-detail. php?grant_id=1656

84. Aviles-Olmos I, Dickson J, Kefalopoulou Z, Djamshidian A, Ell P, Soderlund T, et al. Exenatide and the treatment of patients with Parkinson's disease. J Clin Invest. 2013;123(6):2730-6. http://dx.doi. org/10.1172/JCI68295

85. Athauda D, Maclagan K, Skene SS, Bajwa-Joseph M, Letchford D, Chowdhury K, et al. Exenatide once weekly versus placebo in Parkinson's disease: A randomised, double-blind, placebo-controlled trial. Lancet. 2017;390(10103):1664-75. 